\title{
Remembering the Beatles' Legacy in Hamburg's Problematic Tourism Strategy
}

Stephanie Fremaux and Mark Fremaux

\section{Introduction}

Hamburg's role in the Beatles' legacy has often been overshadowed by the cultural ownership of the band that was claimed by Liverpool's tourism industry in the 1980s and 1990s. Since that time, the National Trust acquired both Paul McCartney and John Lennon's childhood homes, the Cavern Club had been reconstructed and reopened to the public, the Beatles Story Museum at Albert Dock expanded to a second site at the Pier Head, and the upmarket Hard Day's Night Hotel opened on the corners of Mathew Street and North John Street offering rooms up to $£ 950$ a night. However, in May 2009 the city of Hamburg took an important step towards reclaiming the city's Beatles heritage with the opening of the Beatlemania Museum in the Reeperbahn area of the St. Pauli District. Press materials produced to advertise the new museum boldly proclaimed that 'the Beatles have finally come home to Hamburg' (Press Release 2009, p. 1). The museum along with the dedication of Beatles-Platz (Beatles Square) at the end of Große Freiheit in 2008 seemed to signal a new initiative to rebrand Hamburg as a place for family friendly tourism that de-emphasizes the city's infamous reputation as a red-light district. This is also evidenced by the fact that the Beatlemania Museum occupied the five-story building that once housed the Erotic Art Museum. However, as this article argues, Hamburg is a city with conflicting identities. The nostalgia for a past that included a well-known, explicit red light district persists as the Reeperbahn is still associated with seedy strip clubs and brothels where the area's 'two main streets - the Große Freiheit and the Herbertstrasse - form the city's infamous "mile of sin" (Spitz 2005, p. 207). Furthermore, the Toronto Star reported in 2007 that 25 to 30 million people a year visit the St. Pauli district, although there has been a visible shift not only in terms of visitor demographics but also in physical landscape in recent years (Pigg 2007). This is evidenced by the majority of the area's tourists being comprised of young families and late, middle aged couples during the day. At night amongst the Große Freiheit's illuminated neon lights it is more common to see groups of subdued university students participating in pub crawls, and a steady flow of older teenagers posing with the Beatles-Platz statues.

There remains a contingent of old guard residents and businessmen selling pornographic entertainment, collectively known as the St. Pauli Preservation Society, who 
lament the decline of the Reeperbahn's hedonistic heritage. Establishments such as Hotel Luxor, Hamburg's oldest brothel, have closed down and given way to trendier discotheques and bars aimed at the emerging teenage/young adult consumers (Paterson 2008). From 2006 onwards, residents and tourists have witnessed a move towards the gentrification of the Reeperbahn area, but it is by no means being regenerated or invested in at the level of Hamburg's newest harbour front development project, Hafen City (Harbour City). Despite the former senator of finance, Michael Freytag's observation that tourists come to Hamburg to visit the Reeperbahn first, the money invested in the area is vastly insignificant compared to Hafen City's five billion euro inner-city redevelopment budget (Pigg 2007). This new regeneration strategy along Hamburg's waterfront has seen the development of 10 distinct 'neighbourhoods' or quarters, each 'each with their own individual profile' ('Revision of the Masterplan' 2012). For instance, there is an artisan quarter, a commercial and financial quarter, and a 'knowledge' quarter, along with residential and green spaces. Freytag goes on to comment that this investment is due to the awareness of Hamburg's ever increasing 'international image' (Pigg 2007). Yet, it becomes clear upon visiting the Reeperbahn today that as more buildings become vacated and derelict, the streets of the Reeperbahn increasingly deserted, the city seems to be choosing to start fresh by focusing more on the Hafen City project. Because of this lack of investment in the Reeperbahn area, not only has the city been slow to capitalize on Beatles related tourism, but Hamburg's reclaiming of the city's place in the Beatles history is problematic. One of the reasons for this tension is that while the Beatlemania Museum mythologized the memory of the band's brief, but crucial, time in Hamburg by recreating the Große Freiheit of the early 1960s within its walls, the Große Freiheit of today is far from an authentic representation of the past 'Great Freedoms' it was named for. The Reeperbahn of the Beatles' time was a place that defied the conventions and traditions of a conservative, post-war Hamburg by encouraging hedonistic pleasures represented in late night rock ' $n$ ' roll clubs, and legalized prostitution behind the walls of Herbertstrasse. Even the presence of a Catholic church in an otherwise Protestant city symbolizes an anti-establishment attitude. Rather than investing in the street's restoration as a site of musical heritage and embracing the avant-garde art and cafe culture scene hidden down the backstreets, this neglected area is a sad and tame imitation with gaudy strip clubs and abandoned buildings. In addition, a struggle exists between attempts to cater to the lucrative youth market and the redevelopment potential aimed at the upmarket investment clientele. As a result, many of the Beatles' old haunts, such as the Indra Club, the Top Ten, and the Kaiserkeller are passed by without the casual music and Beatles fan realizing these 
establishments' role in cultivating the band's unique sound and style. This article will investigate the problematic nature of Hamburg's relationship to the Beatles, the Beatlemania Museum's function and branding of the Reeperbahn circa 1960-1963, and it will be argued that through these contested spaces, the museum's ability to simulate embodied and emotional attachments to the Beatles' legacy cannot be fully sustained when Hamburg's identity remains fractured.

In regards to musical heritage, the Beatlemania Museum took sole responsibility for aiding individuals in authoring space by creating an emotional attachment first to the recreated Große Freiheit in the museum's exhibition space. Without this key function, the rich musical history of the 1960s that formed meaning and significance for that specific urban space could be lost. This idea will be explored further throughout this piece. It should also be noted that there has not been any research conducted on the aspects of Hamburg as a Beatles tourist destination. To date, the existing scholarship has been focused on how Liverpool developed its musical heritage - museums, statues and public art, sites of Beatles related commerce, etc. - around the band's home town. Works by Cohen (2007), Kruse (2005), and Brabazon (1993) that specifically investigate Beatles related tourism in Liverpool and Gibson and Connell's case study on Memphis (2007) have proven to be invaluable in inspiring this paper's new line of enquiry for Beatles related tourism, and as a result is the first piece to date to provide an in depth investigation of Hamburg's renewed interest in the Beatles' legacy. Connell and Gibson's Sound Tracks: Popular Music Identity and Place and Music and Tourism: On the Road Again provide this research with a theoretical framework with particular reference to how music is used in creating a relationship between physical space, memory, and identity. They discuss the ways in which such cultural sites become contested spaces through a number of factors such as the commodification of music cultures, representations of differing identities in one location, and the influence politics and technology can have on a site's structure (Connell and Gibson 2003, p. x, 9, 15). These are some of the key issues at the heart of Hamburg's urban regeneration and the Beatles' role within that vision.

In the wider context of tourism, heritage and music tourism are direct responses to the increase in traveling for recreation and personal pleasure. With the increasing ease and affordability of traveling in the mid-20th century, tourism focused on catering to individual needs. Postmodernity ushered in a focus on the individual and through the rise of popular culture, consumerism, and the ease of reproduction, museums were no longer exclusive 
spaces for high culture where the relics of an imperial past were on display. Moving away from tourism based around past glories and conquests, tourism became open to a wider range of possibilities with tourists more in favour of actively creating their own, more personalized experiences (Wearing et al 2010, p. 20). Arguably, the role of popular artists, film stars, and literary figures as celebrity helped to create a distinctive opportunity to attract niche audiences. As a 'response to, and rejection of, mass tourism...niche tourism became increasingly significant' (Connell and Gibson 2005, p. 1). Arguably, the role of celebrity culture should not be overlooked as it is built upon the idea of exposing 'the real' and 'the authentic.' If the tourist cannot spend time with their favourite musician or literary figure, spending time in their childhood home, the cottage where they worked, or their grave may allow for a sense of closeness or an understanding of their 'greatness.'

This study does not focus solely on the traditional museum as a site of popular music heritage, but crucially includes analysis of the relationship between place, space, and the tourist by considering how private sector investment has been the key driving force in maintaining an acknowledgement of Hamburg's role in the Beatles' story. Leaver and Schmidt (2009, p. 221) note how music is a catalyst for provoking 'feelings of emotion and nostalgia' and thus make music tourism in all its forms (pilgrimage, festivals, sites of music production, sites of births or deaths, etc) a strong type of tourism to be developed (see also Cresswell, 2004; Connell and Gibson, 2003; Harvey, 1990). However, Hamburg is just one example of the tension between public sector regeneration and private business investment in local neighbourhoods and communities. Frost (2008) notes the drawn out process driven by public policy and competing stakeholders to rename Corporation Lane in Melbourne, Australia, to AC/DC Lane in 2004. In this example, AC/DC had very little connection to this particular street, though the band did have a more concrete link to the city of Melbourne. Other cities like the examples of Liverpool and Hamburg explored in this paper, have more significant links between musicians and place. One such example is Windmill Lane in Dublin which is commemorated with a Rock 'n' Stroll plaque by the city council to denote the use of the nearby studios by $\mathrm{U} 2$. However, this creative hub also includes Windmill Lane Pictures and artwork covering the walls of the lane by local graffiti artists. With each example, there is a debate over what image the city wants to project or to be seen endorsing and how that image fits within the city's overall identity. As with the case of Hamburg, it is a city with conflicting identities, and attempts are being made to overshadow the image of a seedy, out dated past with a more respectable contemporary image of culture, art, and financial stability. 
This paper is also the result of spending a brief period of time embarking on an initial fact finding trip to Hamburg. A good deal of time was spent observing visitors to the BeatlesPlatz statues and talking to the few visitors at the Beatlemania Museum in the summer of 2010. The authors carefully noted how unaware most visitors were to the links to the Beatles that the surrounding area contained. The aim was to gather enough primary research to justify a larger scale project. However, in July 2012 the Beatlemania Museum closed its doors due to the lack of visitors before a return trip could be made. What emerges from this research is a clearer, although no less problematic, picture of the city's mismanagement of multiple, often conflicting identities, and how the Beatles' colourful time in Hamburg also creates a tension when attempting to brand and promote the more family friendly, clean 'Fab Four' image that the populous knows and loves so well.

\section{'From Yesterday to Today': Hamburg's renewed interest in the Beatles}

In May 2008 work began on erecting a public tribute to commemorate the role Hamburg played in the Beatles' legacy. Until the square was officially opened by Hamburg's then mayor, Ole von Beust, in September 2008, there had not been any formal commemorations of Beatles related sites in the St. Pauli district. In addition, the Beatles-Platz project was first discussed in 2005 when local radio station, Oldies 95, established fundraising activities to raise the 100,000 euros needed to begin work ('Beatles Platz planned...' 2005). The initiation of the project by Oldies 95, their work on finding and securing larger investors, and selling certificates acknowledging fan investment all suggest reluctance on the part of the city's government to invest in Beatles and music tourism ('Beatles Platz planned...' 2005). The finished metal outline sculptures of John, Paul, George, Ringo/Pete Best, and Stuart Sutcliffe, based on a concept by architects Dohse and Stich, allow visitors to either pose conventionally with the statues or place their bodies within the outlines. $<<$ Figure 1 > What Beatles-Platz represents is the ambivalence of the local authority towards promoting Hamburg's role in the Beatles' story. However, this ambivalence is not necessarily unique to Hamburg, as Beatles tourist entrepreneurs experienced a similar situation in Liverpool during the 1980s and 1990s. As Cohen (2007, p. 120) points out the Beatles 'left Liverpool for London relatively early on in their career and never returned to live there or to perform there as a band,' and a similar story unfolds with 
the Beatles' time in Hamburg. Much of the initiative in creating Beatles tourism in Liverpool fell to members of the public and public interest groups, rather than being led by the city council. Often this decision to not invest in a music scene can coincide with a city's economic decline since 'music scenes...require constant nurturing and protection' (Cohen 2005, p. 37-38). However, Hamburg's official tourism site records that in 2009, day trippers and overnight guests to the city yielded $€ 6.6$ billion turnover and the city has consistently published a tourism strategy since 2001 (Hamburg Tourist Board 2009, p. 12). Hamburg's Reeperbahn area is ripe for music heritage tourism as most of the original infrastructure still exists and the city does have a strong, legitimate claim in the Beatles' development as musicians and songwriters as the city's clubs had arguably the most effect on shaping the band's image and sound. Inglis (2012, p. 13) notes how the competitiveness and fast changing musical culture in the Reeperbahn clubs provided the Beatles with the experience and connections that would have a strong impact 'in shaping the subsequent direction of their lives and careers' (see also Marshall 2000, p. 169). However, without investing in the Reeperbahn as a site of musical heritage tourism, the clubs in Hamburg are being overshadowed by the preservation and promotion behind Liverpool's Cavern Club where the Beatles were discovered by manager Brian Epstein in November 1961.

Drawing strong comparisons between Hamburg's brief relationship with the Beatles and Liverpool's opens up some insight into the lack of public sector investment in Beatles related tourism in Hamburg as well as explains the difficulty in trying to market a niche experience that took place over a very short period of time. Writing about early Beatles tourism in Liverpool, Cohen (2007, p.160) notes that 'local public sector organizations had not always been that convinced about the merits of promoting the Beatles as a tourist attraction'. Some of the factors cited for this ambivalence are Liverpool's tarnished image, most notably between the 1980s and 1990s when the city was faced with high unemployment and pockets of civil unrest fuelled by social and economic problems that began in the early 1970s, and no 'coherent tourism policy' for the wider range of potential tourist attractions the city could boast (Cohen 2007, p. 160-161). However, in recent years Liverpool has started to thrive as a cultural centre largely attributed to the urban regeneration prompted by the city's Capital of Culture award in 2008. Hamburg on the other hand has always projected an image of affluence and prosperity built upon a successful shipping industry and a long tradition based upon 'the creation and protection of a liberal society through the ideal of Bildung education, cultivation, and improvement' (Jenkins 2003, p. 4). These ideals, on which the city 
of Hamburg based its development since the late nineteenth century, are very much in evidence today in its museums, architecture, green spaces, commerce, and the Hafen City project. For instance, in the area near the Binnenalster section of Alster Lake is Jungfernstieg - the cosmopolitan hub of the city. Jungfernstieg's streets offer designer labels and upmarket department stores, as well as the Colonnaden - a space of arched, arcade-like artisan shops and host to a thriving café and bistro culture. Within a short distance from Jungfernstieg is the Bucerius Art Forum featuring art exhibitions that range from ancient to classic modern, the Deichtorhallen photography gallery housing the Sammlung FC Gundlach collection, the city art gallery (Kunsthalle) which is hailed as 'one of the finest and largest German galleries outside Berlin,' (Murphy 2009, p. 72) and the Art Mile where the Arts and Crafts Museum can be found amongst 'lesser known avant-garde art venues' (Murphy 2009, p. 73). For Hamburg, provincial modernity has dominated over any music tourism agenda, especially when the scene for such liberal entertainment has been extremely localized, segregated even, within the boundaries of the St. Pauli district. Murphy (2009, p. 15) argues that a 'dynamic political scene, a fast growing tourism industry, and a strong economy' have resulted in Hamburg being a forward looking city in terms of development. Perhaps the heady rock ' $n$ ' roll club and sex culture made famous in part by the Beatles in the early 1960s is no longer relevant to Hamburg's tourism agenda and no longer as marketable as it had been in the past? As pointed out by Connell and Gibson (2003, p. 221) music is one key way that "places can be represented in wider mediascapes, shaping local or regional identities'. But for Hamburg, the musical heritage associated with the Beatles' time there can create problems with the image that the city wishes to project not just on a local level, but internationally as well. For instance, the Beatles' time in Hamburg and the rock ' $n$ ' roll music performed represent a time when the city was an industrialized port quickly rebuilding after having been bombed heavily during WWII. There are also references to America's post war cultural imperialism not just within the genre of music, but also found in the iconography of large Coca-Cola signage, the greasy spoon hamburger joints, and retailers of Levis jeans and 'authentic' American cowboy boots. Some of these symbols still exist in and around the Reeperbahn, but largely they are merely whispers of Hamburg's past. One might also argue that a music heritage site like Liverpool has more Beatles related infrastructure already in place that does not necessarily rely on the creation of new spaces but rather relies on the continued maintenance and promotion of those existing spaces. The association of the Beatles with Hamburg has proven to come in at a distant third in relation to Liverpool and London. This idea of the Beatles' relevance to Hamburg's current tourism agenda will be explored in the third section but first, 
it is necessary to analyse Beatles tourism in Hamburg with particular emphasis on the Beatlemania Museum.

\section{'There are places I remember': the Beatlemania Museum and branding the Beatles}

Connell and Gibson (2003, p. 102) argue that 'the most famous scenes' in terms of cultivating a particular musical sound or even in terms of developing a popular site of musical heritage rely heavily upon 'local popular support... and [feature] particularly vibrant combinations of venues, local productions, and methods of information flow and exchange'. While these structures are in place in Hamburg, there seems to be a lack of public and private sector support for promoting and preserving these mechanisms. For example, many of the clubs on Große Freiheit including the Kaiserkeller, 36, Star Club, and the Indra are still in business, although the amount of trade on an average night seems to be lower than what it potentially could be due to the neglect in the buildings' upkeep. In contrast to Hamburg, Liverpool has never stopped producing distinctive musical acts after the Beatles and a strong sense of musical heritage has always prevailed. As Cohen (2007) illustrates throughout her book, the survival of Liverpool as a site of musical heritage was built upon the support by fans and the local musicians who have not left the city, and are still actively contributing to its music scene in some way. Tourism scholars place the most emphasis on 'infrastructures of musical exchange' (Connell and Gibson 2003, p. 102). Examples could include museums, other physical spaces such as streets, houses, and recording studios, active bars and clubs supporting the bands playing the local sound, conventions, and special events commemorating music related anniversaries. Physical spaces in particular are crucial in 'providing concrete spaces' for artists and fans to gather and in also 'emphasizing cultural meaning for participants' (Connell and Gibson 2003, p. 102). So while there are a number of physical spaces in the Reeperbahn area to incorporate around Beatles' tourism and even a wider sense of musical heritage, these venues and sites are not being exploited in any noticeable way. Because of there being no coherent or collective tourism strategy between the clubs and bars on Große Freiheit, most of the onus to provide cultural meaning for the music and Beatles fans who visit the Reeperbahn fell onto the Beatlemania Museum.

The Beatlemania Museum was a five story attraction situated on the Reeperbahn approximately ten feet up from Beatles-Platz and Große Freiheit. Press materials for the 
museum boasted that its eleven distinctive spaces covered over 1,300 square meters that offer 'many original and unusual exhibits on display for the first time' (Press release 2010, p. 1). It goes on to add that 'Everything about BEATLEMANIA is different' as if to set itself apart from other global Beatles sites of musical heritage, most likely the Beatles Story Museum in Liverpool (Press release 2009, p. 1). In addition, knowing that the museum has the potential to be labelled as a niche attraction, the press release assures visitors that the museum is not just for Beatles fans, but that a much wider audience interested in music, sociology, and/or culture can view the museum as a case study for the more general aspects of fandom, merchandising, and music production. What was perhaps the most unique selling point for the museum was that Hamburg's role in the Beatles' story was finally told from the city's perspective allowing for a greater sense of authenticity and accuracy. The exhibition was presented in chronological order starting from the fifth floor and descending down towards the solo years. On the fifth floor, the visitor arrived to find an instant photograph booth to obtain the picture for the 'passport' that doubles as the museum's floor plan. The visitor could choose to have their face framed by the Beatle mop top of their choice (excluding the original, pre-'Fab Four' members Pete Best and Stuart Sutcliffe). Across from the booth were five large windows where enlarged reproductions of the original Beatles' passport photo and information page were on display. Turning the corner into the first exhibition space, the visitor was plunged into near darkness to be faced with a stunning replica of Große Freiheit circa 1960. Amongst the marquees for the Top Ten Club, 36, Kaiserkeller, the Star Club, and TABU, were the iconic photographs of the band showcasing their new image of black leather clothing and 'mop top' haircuts, taken by Astrid Kirchherr at the fairground, a life sized photograph of the enigmatic Sutcliffe standing in a doorway, and a number of photographs, handwritten letters, and original art pieces from the band's time in Hamburg never before seen on display. These artefacts along with the neon lights and video interviews with friends and associates of the band reminiscing about this time period all gave the visitor insight into a period of time that had previously been mythologized and under researched. One can easily argue that there was a greater sense of authenticity and excitement than that provided by the real Große Freiheit mere feet away from the replicated one. Furthermore, with so much space given to Hamburg's narrative, the focus was taken off of prostitution and establishments promoting sex shows and instead emphasis was given to the music and a sense of cultural freedom of expression. This is in great contrast to the Beatles Story Museum in Liverpool where the Hamburg story is briefly told on placards, there is a replica of the Star Club marquee, the iconic life size photograph of John Lennon standing in a doorway taken by 
Jürgen Vollmer in Hamburg, and a life size mannequin of a prostitute. $<<$ Figure 2 > Red is also a key colour used throughout this area on the placards and on the red fencing that leads visitors into this cramped and all too brief exhibition space.

However, the telling of Hamburg's story by the Beatlemania Museum in regards to the Beatles' legacy is problematic due to different versions of Hamburg and the Beatles, strange juxtapositions between the rough and uncultivated image of Hamburg in the early 1960s and the Beatles' 'clean' Beatlemania image. For example, the music being played throughout the museum did not differ from floor to floor to give a sense of transition in the Beatles' development of sound and evolving image. Certain exhibits on the different floors might highlight music from a particular period but these were isolated from the general speaker system. So while walking along the carefully replicated fifth floor - the 'authentic' representation of early 1960s Große Freiheit - amongst the large marquees and neon lights, the music that plays is early Beatlemania, NOT the early recordings of songs the Beatles would have been likely to play in the clubs along the Reeperbahn. Recordings of the Beatles as The Beat Brothers with Tony Sheridan are readily available on CD, including the officially licensed Anthology 1. This problematic imaging of the Beatles could also be seen on the Beatlemania Museum's promotional materials, in the museum's name, and outside at Beatles-Platz. For instance, the museum's official logo - the yellow square with the maroon legend: Beatlemania Hamburg - also features 1969, Abbey Road era Beatles walking across piano keys. Other promotional material, like posters, leaflets, and the online logos feature 1964 Beatlemania era Beatles - mop tops, matching suits, and crucially erroneous to the Hamburg era Beatles, four members instead of five.

The statues at Beatles-Platz also raise issues about the problematic nature of the Beatles as an image. While there are five statues, the four that clearly represent John, Paul, George, and Ringo (who replaced Pete Best in August 1962) are placed in the well-known Beatlemania era stage formation near the centre of the square, whereas the statue of Stuart is separated by some distance to the right of the group. While the placing of Stuart does acknowledge his membership in the original line up and does symbolize the increasing artistic distance he had within the band, it also reinforces the mythology of Stuart Sutcliffe as the enigmatic figure that no one really knows much about. Arguably, this is a mythology that the fifth floor of the Beatlemania Museum tried to undo due to the amount of artefacts on display including handwritten letters, art work, and photographs off stage. The image of a bold artist with an intelligent, witty, and even romantic character starts to emerge. The visitor 
could begin to understand that Stuart Sutcliffe was not just a follower of Lennon, but someone the latter found to challenge and inspire him. Yet this characterization seems to be lost on the majority of casual fans and tourists of the area who did not pay admission into the museum, but rather stopped to pose with and photograph the statues. Because the statues are silhouettes, there is a high propensity for passers-by to align themselves with the outlines and in many instances mime playing the guitar or bass. During the time spent observing the behaviour of the passers-by in regards to their interaction with the statues, no one posed with the Sutcliffe statue, nor did any one stop to reflect on or admire his inclusion in the piece.

However, the interaction by both men and women, young and old, with the statues of the primary four members does reveal interesting ideas in terms of interactivity and meaning making. For instance, interaction with the statues is allowed and encouraged as there is no signage requesting people not to touch the statues. Visitors are able not only to pose with their favourite Beatle, but almost to become their favourite Beatle once their bodies are framed within the statues' outline. Throughout the Beatlemania Museum's eleven different exhibition spaces similar opportunities for interactivity were encouraged. In addition to getting a 'passport' photograph with the visitor's face replacing their chosen Beatle, visitors were also encouraged to enter a space set up like the Abbey Road recording studio and sing along to their choice of an early Beatles hit. Once a satisfactory take has been recorded, visitors could later collect their effort (for a fee) on a USB stick in the gift shop. Another display created a sensory experience that envelopes the visitor in an effort to replicate the overwhelming experience of seeing the Beatles perform at Shea Stadium in 1965 in New York City's borough of Queens. Visitors passed through a heavy black theatre style curtain to enter into an empty white space with two chairs as concert footage of the Beatles performing was projected against the large wall at the front of the space. All of a sudden, the volume of the band decreases while the volume of screaming fans, primarily young girls, increases. As this happened, footage of the screaming fans was projected onto the surrounding walls and ceiling to engulf the viewer in the noise and hysteria. The exhibition dedicated to Sgt. Pepper's Lonely Hearts Club Band (1967) featured a large cardboard display of the Sgt. Pepper album cover. Visitors could either stand behind the cut outs at the top to blend in with the likes of Edgar Allan Poe, Mae West, and Bob Dylan or stand at the front next to or in front of the Beatles while holding the tuba or touching the bass drum. From these examples we can see that the Beatlemania Museum was able 'to provide a social space for expression and role reinforcement'through the interactive displays and exhibits by allowing visitors the 
chance to position their own lives and memories in relation to the Beatles (Wearing et al 2010, p. 40). From the highly interactive opportunities such as the statues at Beatles Platz or the karaoke style recording booth, visitors were able to engage in " "playing" with role identities' and even 'develop individual identities apart from those associated with' other roles they 'perform' on a daily basis (Wearing et al 2010, p. 40). Even the standard video consoles allowed visitors access to information in a way that let the visitor comment to their companions. This simple decision to eschew personal headphone sets encouraged visitors to share comments, stories, experiences, and memories of the Beatles; by contrast with the headphone sets handed out at the Beatles Story in Liverpool, visitors tend not to interact with each other and instead wander around the museum almost unaware of those around them occupying the same space. There is also an eerie, funereal like silence that dominates large sections of exhibition space (see Connell and Gibson 2007). Arguably, these audio tours, though useful in providing the visitor with extra information that could not be practically delivered on signage or through staff guided tours, discourage interaction and meaning making.

\section{'You won't see me': The Beatles' place in Hamburg's future}

By recreating Große Freiheit of the 1960s within its walls, the Beatlemania Museum took on the function of preserving the nostalgia for Hamburg's red light district and rock ' $n$ ' roll past. Research conducted for this piece has shown time and again that there are strong links between music heritage and nostalgia. This link with nostalgia can be very positive and attractive for tourist agencies in building tourism attractions. For example, Kruse (2005, p. 91) argues that the 'dominant discourse of the Beatles in Liverpool (young, vital, playful) helps to locate visitors within a similar optimistic and youthful place within their own emotional geographies'. And there are initiatives at the Beatles Story in place to accommodate a wide age range of visitors - from the children's learning zone to the Fab 4D experience. Upon closer examination of exhibits on display at the Beatles Story there is an awareness of audience and how the Beatles can be presented to different generations who each bring their own vision and interpretation of the band's image. It all works very well with the more innocent, mop top images of the Beatles, and even the band's experimentation with the counterculture is sanitised for younger visitors. The heady period of LSD that yielded Sgt. Pepper and Yellow Submarine is presented in a very colourful, cartoon-like fashion with 
funfair mirrors and the inside of the yellow submarine recreated. While the Beatlemania Museum, on the other hand, had acknowledged the prostitution and sexual freedoms experienced in the area in the 1960s, it also provided a greater insight into the atmosphere of the rock ' $n$ ' roll scene in Hamburg at that time. This is an issue that Beatles related tourism ventures have had to consider in Liverpool. More often than not, Liverpool projects a Beatles story where 'unpleasantries [are] dropped from history, and stories of the past [are] told in the carefully (and commercially) remythologized form' (Kruse 2005, p. 111). However, for Hamburg there may be an apprehension by the city's council that the more colourful aspects of the Reeperbahn and the Beatles' history could be seen to be linked with the city's projected image or be seen to be endorsed by the city (see Frost 2008). The Beatlemania Museum did foreground the Beatles' time in Hamburg and established a context for what the area was like in the 1960s with all of its hedonism. Kruse (2005, p. 91) cites Goss (1999, p. 47) who argues that there is a tendency for nostalgia to become manifested as 'anxiety felt about the direction and pace of social and technical change' that becomes 'sublimated in a poignant regret and melancholy longing for a past'. If the city of Hamburg is more focused on investing in urban regeneration, then there is perhaps a more viable tourism venture to be had in the area of urban tourism.

As mentioned previously, the Hafen City project illustrates that the city is increasingly less nostalgic about its past. The argument that Hafen City is to be the new vision and the new focus of Hamburg's regenerated image is evidenced in a number of ways. For instance, Hafen City has been divided into distinctive quarters. In this way, the area can be organized into specific centres, rather than having these centres grow and mingle organically as they do throughout the Reeperbahn and other parts of Hamburg. Hafen City also looks as though it could easily replace the Reeperbahn as the city's main theatre and cultural district as the Elbphilharmonie Concert Hall, the International Maritime Museum, the Hamburg-America Centre, and the Hamburg Dungeons are currently open for business. This area, along with the Landungsbrücken district directly across the river, is a prime example of the type of urban tourism Wearing et al (2010, p. 87) describe as being increasingly popular with city tourism boards. In Hamburg, tourists can visit the Maritime Museum and experience one of the many boat tours of the river and harbour that include a tour of the container ship loading docks and other similar shipping infrastructure. By comparison, Murphy (2009, p. 40, 115-116) describes the St. Pauli district as 'tacky,' offering primarily niche entertainment in the form of variety shows, cabaret, bars offering lap dancing, and 
without much in the way of worthwhile markets. Connell and Gibson (2005, p. 117) note how such initiatives benefit 'visitors and upwardly mobile professionals' over the working class. In this case, national identity is a far stronger and more sustainable tourism strategy for the city as a whole so the city invests in a maritime heritage that encourages gentrification of the area. As St. Pauli still attracts its visitors, it is viewed as a niche market but it does not have the potential or the image to warrant large scale investment from the city. $<<$ Figure 3 >> The independent artisan community of St. Pauli and nearby Sternschanze may have enough local support and the support of lower but steady tourism to survive but it does not seem to be a sustainable business model from which to rebrand the whole of Hamburg.

Previously, Hamburg has been overlooked by larger and more obvious tourist destinations in Germany such as Berlin and Munich. However, arguably due to the attention and high investment funds being used to develop Hafen City, Hamburg is emerging as a real rival to both cities. This is evidenced not only in the amount of money being spent on developing the area, but also in its sheer size. According to Murphy (2009, p. 88), Hafen City and the surrounding dock area of Hamburg is one of two of the largest harbours in Europe with 27 miles of quays and over 300 shipping lines importing and exporting goods through Hamburg each year. The creation and development of Hafen City also allows the city of Hamburg greater control over the identities representing each quarter. Whereas St. Pauli organically emerged as the red light district due to its proximity to the landing docks further down from the city centre. The long streets in the area, including the half mile long Reeperbahn (meaning 'Rope Walk'), allowed for large scale rope to be manufactured for merchant ships. Both Liverpool and Hamburg have developed their industrial sites into opportunities for tourism. Liverpool's Ropewalks has been described as the city's "independent and creative quarter" with a website that argues the best shopping, fashion, art, culture, and music entertainment can be found there (Ropewalks 2010). Where the Reeperbahn has been left underdeveloped, the city of Liverpool has been more successful in regenerating these spaces. Liverpool's Ropewalks is an area of conservation and protected by its UNESCO heritage status. While the area's website is steeped in nostalgia for the city's shipping and industrial past, the key difference between the two Ropewalks is that Liverpool's has encouraged new businesses into the area with the selling point of "creative cool," and "hip and arty" (Ropewalks 2010). Yet, in Hamburg, the Reeperbahn still clutches onto its red light past for heritage tourism. 
St. Pauli is physically separated from the affluent Altona suburb by a major road, the Holstenstrasse, and a series of large parks (Wohlers Park, Walter Müller Park, and Jüdischer Friedhof) that create a distinctive barrier between the two districts. By contrast, the Hafen City quarters have been carefully planned to accommodate the different types of city approved culture, commerce, and clientele in carefully segregated blocks. One such example is the Oberhafen neighbourhood. Originally, the city planners had designated this area a commercial and industrial site. Upon closer analysis the Hafen City project website's information on Oberhafen is quite telling. The article uses a photograph of a heavily graffitied wall next to an overgrown rail line and disused platform. In addition, the article discloses the fact that the site lacks flood protection. Therefore, it seems as if marking Oberhafen out as a 'creative and cultural quarter' may prove to be more financially sound considering the potential threat of flooding ('Oberhafen Neighbourhood' 2012). Also in contrast to St. Pauli and the Reeperbahn, Oberhafen provides the city with a clean slate. Despite its image, however, walking around the St. Pauli district did uncover the rich diversity and creative community already in existence in the area with a tapestry of large scale graffiti art, a youthful and vibrant café and pub scene, and independent clothing and record shops in desperate need of council support. The infrastructure is already in place with cultural minded inhabitants, but without financial backing and promotion of the area there is a risk that this community will be overshadowed by the city endorsed Oberhafen neighbourhood. What might also attract new cultural related commerce into the neighbourhood is the city's plan to set the buildings (a mixture of old warehouses and new builds) at a lower budget than the properties available in the other neighbourhoods designated for business and upmarket residents like the Elbbrücken neighbourhood ('Oberhafen Neighbourhood' 2012). By creating neighbourhoods in Hafen City with such specific planning and promotional materials in English to attract a global audience, it is clear to see that the city council and tourist board are determined to control Hamburg's overarching identity as much as possible.

\section{Conclusion}

It should be stressed that the contested spaces that have emerged in Hamburg as a result of the city's urban regeneration initiative are nothing new. Cities such as Detroit, Michigan, in the USA, Liverpool, Manchester, and Newcastle in the UK, and Amsterdam in 
Holland all have dealt with or are currently dealing with this very issue of promoting a central identity (McCarthy 2002; Cohen 2007; Bottà 2009; Vall 2007). The situation is all the more problematized by cities with strong links to industrial heritage. For Hamburg, the city's preexisting arts and culture infrastructure and maritime heritage provide an opportunity 'to create distinct place identities' focused on "“cultural tourism," involving the commodification of local culture and heritage, and to interconnections between tourism, art, education, [and] shopping...'(Cohen 1997, p. 72). As this research has shown, Hamburg is a city that is not lacking in museums, striking architecture, and well known market sites. Rather than invest in space whose identity is entrenched in local and international memory, Hafen City enables the city to create a fresh, new, and orderly urban image to allow the city of Hamburg to establish itself as a serious competitor to many of the more well-known European city centres. The city has chosen to ignore potential reinvestment strategies around St. Pauli because the financial benefits of tourism and commerce around Hafen City are more viable (Connell and Gibson 2005, p. 44). When comparing Liverpool's successful hold on Beatles tourism to Hamburg, one of the primary differences between the cities is the strong links to popular music culture that already existed in Liverpool. As Cohen (2007, p. 221) attests, the regeneration of Liverpool included a strong link 'between popular music and the city [that] were held dear and were fiercely protected...' Arguably, the role of popular music and popular music infrastructure is not significant enough for Hamburg to invest in when there already exists a thriving cultural industry; whereas for Liverpool, recent urban development of the dock area along the Mersey has seen an attempt to diversify the city's tourism agenda by renewing its maritime history along with the creation of the Museum of Liverpool in which popular music only plays a small part in the collections. The initial analysis of Hamburg's tourism agenda that this article provides suggests new avenues for research, particularly in comparing not only how both cities have incorporated their roles in the Beatles' story as a tourist attraction, but also in examining how each city has dealt with contested space. The similarities between Liverpool and Hamburg's physical landscape and history is uncanny, yet this initial research has begun to uncover great differences in the development of their tourism and regeneration policies, their image, and their use of contested spaces.

For the average tourist visiting Hamburg and for the mainstream Beatles fan, the museum may be enough to allow the visitor to satisfy the key results of being a tourist - to participate, experience, and learn even if this is done on a superficial level through a recreated space rather than the authentic space (Wearing et al 2010, p. 32). This research 
highlights that there is tension between disappointment at Hamburg's city council not making more of these sites of popular music heritage around the St. Pauli district and the joy of being a 'true' Beatles fan evidenced by knowing where the actual venues were located, being able to share trivia prompted by the displays and the interactive opportunities. Wang (1999, p. 29 cited in Wearing et al 2010) argues that the latter actually creates an experience where authenticity is subjective to each tourist and therefore allows the tourist access to 'an enhanced and enlarged sense of the traveller self.' In this way, the traveller actually enjoys a more personalized narrative that will not be the same as another traveller's experience. Spencer Leigh's 2011 publication made in conjunction with the Beatlemania Museum does go some way in presenting the history of the Beatles' legacy in Hamburg to the populous but the existing infrastructure of many key sites is in poor condition. Hamburg's claim on the Beatles' legacy can be explained and justified as fulfilling a very satisfying experience for the 'true' Beatles fan as well as providing an 'authentic' experience for more general Beatles and music fans even though the city has not invested in their musical heritage to the extent of Liverpool in the UK, or Nashville, Tennessee, and New Orleans in the US. For example, the Beatlemania Museum in Hamburg did allow visitors the opportunity to walk through the Beatles' history chronologically with a number of familiar and the rarer artefacts on display to satisfy both parties. Wearing et al (2010, p. 34) have explained this function that the museum fulfils by arguing that the focus is very much on the individual instead of the experience as a whole because visitors place different values on different activities and sites from each other and that they 'negotiate space in different ways.' This type of experience for the traveller can be used by academics to explain positively the little investment the city has put into Beatles and music tourism - it occurred out of the practicalities of low levels of funding. But Brabazon (1993, p. 114) sees Hamburg's half-hearted claim on the Beatles differently. She argues that the success of Liverpool as a site of musical heritage centred on the Beatles, and the Beatles building their image around a Liverpudlian identity, created a kind of monopoly on the band that resulted in other sites of the Beatles' history being 'deemphasized.' This suggests that it would be very difficult for cities like London and Hamburg to build a tourism initiative solely around the Beatles. As a result, the Beatlemania Museum alone, as this article has illustrated, fulfilled this function for the music tourist. In addition, on one hand it could be argued that the lack of commercialisation around music and Beatles tourism in the St. Pauli district creates an opportunity for a more authentic experience for the traveller. The landscape the music tourists finds is largely untamed by the more obvious attempts to cash in on the Beatles' brand and clubs like the Kaiserkeller and Große Freiheit 
36 still showcase a good variety of rock ' $n$ ' roll acts. On the other hand, the Top Ten Club is deserted without so much as a plaque denoting its part in the Beatles' history, the Indra Club sits nearly vacant at the far end of Große Freiheit, and the rebuilt Star Club is hidden off Große Freiheit down a narrow passageway. As this research has shown, tourism allows for the 'revitalization, preservation, and also the destruction of cultural phenomena, and creates new landscapes' (Connell and Gibson 2005, p. 3). The primary concern, however, is what the future holds for the city's claim on Beatles heritage now that the Beatlemania Museum has closed due to the difficulties in maintaining the current level of vested interest without increased support and monetary investment into the area. Only 150,000 visitors had experienced the exhibition since its opening in May 2009 ("End of Beatlemania..." 2012). As the museum's manager, Folkert Koopmanns, argued the museum's failure was due to the lack of support from Hamburg's city council, stating 'A privately-run museum as big as Beatlemania is condemned to fail without public support' ("End of Beatlemania..." 2012). What is of concern, unfortunately, is if Hamburg's role in the Beatles' story should fade away slowly as the city moves further from its industrial, red light past into a future of urban and cultural regeneration. 
The authors wish to acknowledge the generosity of Dr. Rachel Carroll, principle lecturer in research at Teesside University, for encouragement, feedback and editorial advice.

\section{$\underline{\text { References }}$}

“All You Need Is...Beatlemania Hamburg." (2009). Press Release.<http://www.beatlemaniahamburg.com/downloads/2009_05_14_PM_Beatlemania_Information.pdf>. [Accessed 24 January 2012]

"Beatlemania Hamburg: The New Beatles World on Hamburg's Reeperbahn." (2010). Press Release. $<\mathrm{http}: / / \mathrm{www}$. beatlemaniahamburg.com/downloads/2009_05_29_PM_Beatlemania_Concept.pdf >. [Accessed 24 January 2012]

"Beatle-Platz Planned for Hamburg." (2005) BBC News Online. 28 September <http://news.bbc.co.uk/1/hi/entertainment/music/4289594.stm>. [Accessed 11 March 2013]

Bottà, G. (2009) "The City that was Creative and did not know it: Manchester and Popular Music 1976 - 97." European Journal of Cultural Studies. 12(3). 349 - 365.

Brabazon, T. (1993) "From Penny Lane to Dollar Drive: Liverpool Tourism and a Beatle-led Recovery." Public History Review. 2. 108 - 122.

Cohen, S. (1997) "More than the Beatles: Popular Music, Tourism, and Urban Regeneration." In Tourists and Tourism: Identifying with People and Places. Eds. Simone Abram, Jacqueline Waldren, and Donald V.L. Macleod. Oxford: Berg. 71 - 90.

---. (2005) "Country at the Heart of the City: Music, Heritage, and Regeneration in Liverpool.” The Society for Ethnomusicology. 49(1). 25 - 48.

---. (2007) Decline, Renewal, and the City in Popular Music: Beyond the Beatles. Aldershot: Ashgate Publishing Limited.

Connell, J. \& Gibson, C. (2003) Sound Tracks: Popular Music, Identity, and Place. London: Routledge.

---. (2005) Music and Tourism: On the Road Again. Bristol: Channel View Publications.

---. (2007) "Music Tourism and the Transformation of Memphis."Tourism Geographies. 9(2). $160-190$.

Cresswell, T. (2004) Place. Oxford: Blackwell. 
"End of Beatlemania: Beatles museum in Hamburg closes its doors." (2012) The Telegraph. 06 June. <http://www.telegraph.co.uk/culture/music/the-beatles/9313080/End-ofBeatlemania-Beatles-museum-in-Hamburg-closes-its-doors.html>. [Accessed 21 March 2013].

Frost, W. (2008) "Popular Culture as a Different Type of Heritage: The Making of AC/DC Lane." Journal of Heritage Tourism. 3(3). 176 - 184.

Goss, J. (1999) "Once-upon-a-Time in the Commodity World: An Unofficial Guide to the Mall of America." Annals of the Association of American Geographers. 89(1). 45 75.

Hamburg Tourist Board. (2009) Hamburg Tourism Monitor: Facts, Figures, \& Trends. Hamburg: Hamburg Tourismus GmbH. <http://www.hamburgtourism.de/fileadmin/files/B2B/Zahlen_und_Fakten/Studien_Publikationen/HHT_ZF T_brosch_eng_05.pdf> [Accessed 11 March 2013]

Harvey, D. (1990) The Condition of Postmodernity: An Inquiry into the Origins of Cultural Change. Oxford: Blackwell.

Inglis, I. (2012) The Beatles in Hamburg. London: Reaktion Books Ltd.

Jenkins, J. (2003) Provincial Modernity: Local Culture \& Liberal Politics in Fin-De-Siècle Hamburg. Ithaca, NY: Cornell University Press.

Kruse II, R. J. (2005) “The Beatles as Place Makers: Narrated Landscapes in Liverpool, England." Journal of Cultural Geography. 22(2). 87 - 114.

Leaver, D. \& Schmidt, R.A. (2009) "Before They Were Famous: Music-based Tourism and a Musician's Hometown Roots.” Journal of Place Management and Development. 2(3). 220- 229.

Leigh, S. (2011) The Beatles in Hamburg. London: Omnibus Press.

McCarthy, J. (2002) “Entertainment-led Regeneration: the Case of Detroit.” Cities. 19(2). $105-111$.

Marshall, P. D. (2000) “The Celebrity Legacy of the Beatles.'In The Beatles, Popular Music and Society.Ed. Ian Inglis. Basingstoke: Macmillian Press. 163 - 175.

Murphy, P. (2009) Hamburg. Peterborough: Thomas Cook Publishing.

Paterson, T. (2008) "Death of the Reeperbahn: Hamburg's Streets of Shame." The Independent. 21 March. <http://www.independent.co.uk/news/world/europe/death-ofthe-reeperbahn-hamburgs-streets-of-shame-799034.html>. [Accessed 11 March 2013]

Pigg, S. (2007) "Harbouring Grand Ambitions.” The Toronto Star. 25 August. <http://www.thestar.com/article/248794>. [Accessed 11 March 2013] 
"Revision of the Masterplan: Oberhafen Neighbourhood." (2012)

$<$ http://www.hafencity.com/en/revision-of-the-master-plan/oberhafenneighborhood.html>. [Accessed 11 March 2013]

"Revision of the Masterplan: Taking the Hafen City Concept Further." (2012) $<$ http://www.hafencity.com/en/revision-of-the-master-plan/revision-of-themasterplan-taking-the-hafencity-concept-further.html >. [Accessed 11 March 2013]

"RopeWalks." (2010) < http://www.ropewalksliverpool.com/>. [Accessed 11 March 2013]

Spitz, B. (2005) The Beatles: The Biography. New York: Back Bay Books.

Vall, N. (2007) Cities in Decline? A Comparative History of Malmö and Newcastle. Malmö: Malmö University Press.

Wang, N. (1999) "Rethinking Authenticity in Tourism Experience." Annals of Tourism Research. 26(2). 349-70.

Wearing, S., Stevenson, D., \& Young, T. (2010) Tourist Cultures: Identity, Place, and the Traveller. London: Sage.

Whitely, S., Bennett, A., \& Hawkins, S. (Eds) (2004) Music, Space and Place: Popular Music and Cultural Identity. Aldershot: Ashgate Publishing Limited. 